\title{
Adjunctive Statin Therapy Reduces Mortality After Acute Hemorrhagic Stroke
}

This article was published in the following Dove Press journal:

Risk Management and Healthcare Policy

\author{
Cheng-Kai Lin ${ }^{1,2}$ \\ Po-Yuan Chen ${ }^{1,2}$ \\ Yu-ying $\mathrm{Wu}^{1,2}$ \\ Cheng-Chun Wu' \\ Han-Jung Chen ${ }^{1,2}$ \\ Cheng-Loong Liang ${ }^{1,2}$ \\ Yi-Che Lee (iD) ${ }^{1,3}$ \\ Chi-Wei Lin ${ }^{1,4}$ \\ Chao-Ming Hung ${ }^{1,5}, *$ \\ Hao-Kuang Wang (iD) ${ }^{1,2,6, *}$ \\ 'School of Medicine, College of Medicine, \\ I-Shou University, Kaohsiung, Taiwan; \\ ${ }^{2}$ Department of Neurosurgery, E-Da \\ Hospital, Kaohsiung, Taiwan; ${ }^{3}$ Department \\ of Nephrology, E-Da Hospital, Kaohsiung, \\ Taiwan; ${ }^{4}$ Department of Family Medicine, \\ E-Da Hospital, Kaohsiung, Taiwan; \\ ${ }^{5}$ Department of General Surgery, E-Da \\ Cancer Hospital, Kaohsiung, Taiwan; \\ ${ }^{6}$ Department of Neurosurgery, E-Da \\ Cancer Hospital, Kaohsiung, Taiwan \\ *These authors contributed equally to this \\ work
}

Correspondence: Chao-Ming Hung; HaoKuang Wang

Department of Neurosurgery, E-Da Hospital/I-Shou University, No. I, Yida

Road, Jiaosu Village, Yanchao District,

Kaohsiung City 82445, Taiwan

Tel +866-975I06080

Email ed100647@edah.org.tw;

edI01393@gmail.com
Background: Statin treatment improves clinical outcomes in patients with ischemic strokes, although there is no evidence regarding the safety of statin therapy in patients with intracerebral hemorrhage (ICH). This study aimed at evaluating the effects of continuing statin treatment after ICH.

Methods: Data were obtained from the National Health Insurance Research Database in Taiwan. We retrospectively compared the data of patients with and without statin exposure after ICH. The outcomes of interest were recurrence of hemorrhagic stroke and mortality during a follow-up period of 10 years.

Results: During the 10-year follow-up period, the mortality rate was $32.73 \%$ in the statin group and $42.77 \%$ in the non-statin group. Statin therapy in patients with acute ICH with dyslipidemia can decrease mortality.

Conclusion: Statin therapy reduced the risk of 10-year mortality in patients who experienced acute hemorrhagic stroke.

Keywords: statin, hemorrhagic stroke, mortality

\section{Background}

Intracerebral hemorrhage (ICH) causes only approximately $10-20 \%$ of all strokes, ${ }^{1}$ and this stroke subtype does not have a scientifically proven treatment. Intracerebral hematoma volume, expansion of intracerebral hematoma, age, Glasgow Coma Scale, and intracerebral hematoma location are the factors influencing ICH mortality and outcomes, of which only the expansion of intracerebral hematoma can be biologically modified. ${ }^{1,2}$ Therefore, ICH has a high case fatality rate and poor functional outcome.

3-Hydroxy-3-methylglutaryl coenzyme A reductase inhibitors or "statins" are effective in lowering low-density lipoprotein cholesterol (LDL-C). They can also improve endothelial function, modulate thrombogenesis, attenuate inflammatory and oxidative stress damage, and facilitate angiogenesis. Therefore, statins have been proven to significantly decrease the risk of ischemic stroke and improve clinical outcomes. ${ }^{3}$ Furthermore, there exists a noteworthy association between low cholesterol levels and ICH. The lower the cholesterol level, the higher the risk of $\mathrm{ICH}$, suggesting a possible U-shaped association between cholesterol and stroke. ${ }^{4}$ This has led some clinical practitioners to avoid the use of statins in cases of ICH survivors, particularly in men with hypertension. Therefore, there is no conclusive evidence to suggest the safety of statins in ICH survivors.

The goal of our study was to determine whether statin treatment has an effect on the recurrence of ICH and mortality in patients with a history of ICH. 


\section{Methods}

\section{Database}

In this retrospective cohort study, data were obtained from the National Health Insurance Research Database (NHIRD), which almost covers the entire 23 million population of Taiwan. ${ }^{5,6}$ Taiwan officially commenced its National Health Insurance (NHI) program on 1 March, 1995 to finance healthcare for all its citizens. At the end of 2012, 23.0 million individuals, representing $99 \%$ of the Taiwanese population, had been enrolled in this program. The NHIRD comprises de-identified secondary data that are publicly available for research purposes. Details on database generation, monitoring, and maintenance are published online (http://nhird.nhri.org.tw/). The Research Ethics Committee of E-da Hospital approved the study protocol (EDAD 2014).

\section{Study Sample}

Patients to be included in the study were selected from the database using the International Classification of Disease, 9th Revision, Clinical Modification diagnostic code for ischemic stroke $(433,434)$ and ICH (431) on the basis of their hospitalization discharge records from January 1, 2000 to December 31, 2012. ${ }^{6-8}$ Those patients must have a catastrophic illness certificate of ischemic stroke or ICH in Taiwan. We excluded patients who died within 1 year, patients with ischemic stroke, and patients aged $<50$ years to restrict the study to the assessment of high risk of rebleeding. We also excluded patients who had a recurrence of ICH within 1 year because of the difficulty in examining the effects of statin administration. Because patients who quit taking statins 3-6 months after having an ischemic stroke were $42 \%$ more likely to experience a second stroke within 6-18 months. ${ }^{9}$ There was no increased risk for people who continued to take statins at a reduced dose. Therefore, patients prescribed with statin treatment $<6$ months after the index ICH were excluded. Finally, the remaining patients were included for further analysis. After matching propensity scores, 1702 patients were enrolled in the statin group and 1702 patients were enrolled in the nonstatin group, and their clinical outcomes were analyzed.

\section{Main Outcome Measures}

The primary outcomes included all-cause mortality and recurrence of ICH. All-cause mortality was defined by withdrawal from the NHI program. Recurrence of ICH outcomes was defined as a principle diagnosis for hospitalization for ICH 1 year after the index date. The patients were followed-up until their death or the end of the study (December 31, 2015), whichever occurred first.

\section{Statistical Analyses}

We performed propensity score matching to reduce treatment selection bias with a $1: 1$ ratio in which each patient in the statin group was matched with a corresponding patient in the non-statin group. The patient characteristics between the study groups were compared using the chisquare test for categorical variables and the $t$-test for continuous variables. Then, we compared those characteristics between the study groups using the multivariate Cox regression analysis controlling for demographic data, and medications. A p-value $<0.05$ was considered to be statistically significant. All statistical analyses were performed using a commercial software (SAS 9.4, SAS Institute, Cary, NC, USA).

\section{Results}

After applying the exclusion criteria, a total of 51,442 ICH patients with at least one incident of $\mathrm{ICH}$ were included in the analysis. After matching propensity scores, 1702 patients who received statins after ICH were compared with 1702 patients who did not receive statins. There were no significant differences in the majority of the baseline characteristics between the two groups. Only cerebrovascular disease was significantly different between the non-statin and statin groups. In terms of medication, the statin group had higher prescription rates of anticoagulant agents, antihypertensive agents, non-steroidal antiinflammatory drugs (NSAIDs) (including cyclooxygenase-2 inhibitors), and selective serotonin reuptake inhibitors (SSRIs) than the non-statin group (Table 1).

The all-cause mortality rate was $32.73 \%$ in the statin group and $42.77 \%$ in the non-statin group after 10 years of follow-up. There was no significant difference in the rate of recurrent ICH between the two groups at the 10 years follow-up (Table 2, and Figure 1). Both the statin therapy and anticoagulant therapy resulted in significantly lower 10-year mortality rates (Table 3 and Figure 2). During the 10-year follow-up period, there was higher mortality due to ischemic stroke in the non-statin group than in the statin group (Table 4). We performed two subgroup analyses, wherein we first analyzed ICH and mortality stratified using the 23 pre-specified baseline characteristics. The results showed that the observed protective effect against 
Table I Baseline Characteristics of the Intracerebral Hemorrhage Population

\begin{tabular}{|c|c|c|c|}
\hline & $\begin{array}{l}\text { Non-Statin } \\
\text { Cohort } \\
N=1702\end{array}$ & $\begin{array}{l}\text { Statin } \\
\text { Cohort } \\
N=1702\end{array}$ & p-value \\
\hline Age & $63.55 \pm 9.03$ & $63.78 \pm 9.15$ & 0.4574 \\
\hline Gender & & & $>0.9999$ \\
\hline Female & $774(45.48)$ & $774(45.48)$ & \\
\hline Male & $928(54.52)$ & $928(54.52)$ & \\
\hline \multicolumn{4}{|l|}{ Medication } \\
\hline Antithrombotic agents & $0(0.00)$ & $0(0.00)$ & - \\
\hline Anticoagulant agents & $15(0.88)$ & $35(2.06)$ & 0.0044 \\
\hline Antihypertensive agents & I I84(69.57) & $1546(90.83)$ & $<0.0001$ \\
\hline NSAIDs & $274(16.10)$ & $495(29.08)$ & $<0.0001$ \\
\hline SSRIs & $564(33.14)$ & $767(45.06)$ & $<0.0001$ \\
\hline \multicolumn{4}{|l|}{ Comorbidities } \\
\hline Myocardial infarct & $63(3.70)$ & $78(4.58)$ & 0.1970 \\
\hline Congestive heart failure & $104(6.11)$ & $127(7.46)$ & 0.1170 \\
\hline Peripheral vascular disease & $47(2.76)$ & $45(2.64)$ & 0.8326 \\
\hline Cerebrovascular disease & $562(33.02)$ & $629(36.96)$ & 0.0160 \\
\hline Dementia & $45(2.64)$ & $51(3.00)$ & 0.5345 \\
\hline Chronic lung disease & $445(26.15)$ & $438(25.73)$ & 0.7843 \\
\hline Connective tissue disease & $34(2.00)$ & $20(1.18)$ & 0.0548 \\
\hline Ulcer & $464(27.26)$ & $501(29.44)$ & 0.1594 \\
\hline Chronic liver disease & $252(14.81)$ & $249(14.63)$ & 0.8846 \\
\hline Diabetes & $483(28.38)$ & $482(28.32)$ & 0.9697 \\
\hline $\begin{array}{l}\text { Diabetes with end organ } \\
\text { damage }\end{array}$ & $136(7.99)$ & $132(7.76)$ & 0.7991 \\
\hline Hemiplegia & $24(1.4 I)$ & $22(1.29)$ & 0.7665 \\
\hline $\begin{array}{l}\text { Moderate or severe } \\
\text { kidney disease }\end{array}$ & $117(6.87)$ & $126(7.40)$ & 0.5491 \\
\hline Tumor, leukemia, lymphoma & $67(3.94)$ & $72(4.23)$ & 0.6650 \\
\hline Malignant tumor, metastasis & $10(0.59)$ & $9(0.53)$ & 0.8180 \\
\hline AIDS & $0(0.00)$ & $0(0.00)$ & - \\
\hline
\end{tabular}

Table 2 Outcome of the Intracerebral Hemorrhage Population

\begin{tabular}{|l|l|l|l|}
\hline & $\begin{array}{l}\text { Non-Statin } \\
\text { Cohort N=I702 }\end{array}$ & $\begin{array}{l}\text { Statin Cohort } \\
\mathbf{N}=1702\end{array}$ & p-value \\
\hline $\begin{array}{l}\text { Intracerebral } \\
\text { hemorrhage } \\
\text { Death }\end{array}$ & I7I(10.05) & $153(8.99)$ & 0.2931 \\
\hline
\end{tabular}

$\mathrm{ICH}$ was more apparent in the younger age group and in female subjects (Table 5).

\section{Discussion}

There have long been concerns about the association between statin treatment and ICH. This study showed that mortality improved and did not worsen the recurrence of $\mathrm{ICH}$ in patients receiving statin treatment after $\mathrm{ICH}$ compared with those not receiving statin treatment. During the 10-year follow-up period, the mortality rate was $32.73 \%$ in the statin group and $42.77 \%$ in the nonstatin group. There were no significant differences in the rate of recurrent $\mathrm{ICH}$ between the two groups at 10-year follow-up evaluation (10.05 vs 8.99; $\mathrm{p}=0.293$, respectively). Our study also demonstrates that female patients appear to benefit more than male patients. These results indicate that statin therapy in acute ICH patients with dyslipidemia can decrease mortality.

Atherosclerosis arises due to the accumulation of LDL$\mathrm{C}$ leading to inflammatory processes in the endothelial cells of the vessel wall. ${ }^{9}$ These processes can stretch the muscle cells of the blood vessels, compensating for the additional bulk. Furthermore, the endothelial lining thickens, increasing the separation between the plaque and lumen, ${ }^{10,11}$ that can ultimately cause a heart attack, stroke, or peripheral vascular disease. Statins have a variety of properties, including anti-inflammatory, anti-thrombotic, and antioxidant effects, stabilization of atherosclerotic plaque, and enhancement of clot lysis. ${ }^{2,12-15}$ In addition to the positive effect of statin therapy has shown an association between statin therapy and reductions in a variety of other endpoints, including ischemic stroke, heart failure, and coronary artery disease. Stroke patients often have other comorbidities and die from other causes (infarction, ischemic stroke, thromboembolism, etc.) that have been shown to be influenced by the use of statins. Therefore, statin treatment was used not only to prevent ischemic stroke but also to improve functional outcome.

In contrast, a U-shaped association exists between cholesterol and stroke. LDL is positively associated with risk of ischemic stroke and negatively associated with risk of hemorrhagic stroke. In a population-based prospective study, a significant correlation was observed between lower LDL-C levels and higher ICH risk, especially when LDL-C level was $<70 \mathrm{mg} / \mathrm{dL} .{ }^{16,17}$ Additionally, low LDL-C levels are strongly and independently associated with increased risk of cancer, cerebrovascular disease, and all-cause mortality. ${ }^{18,19}$ Therefore, the influence of statin treatment after ICH on functional outcomes, mortality, or risk of recurrence is unknown. ${ }^{20-26}$ Our nationwide cohort study of patients with newly diagnosed $\mathrm{ICH}$ demonstrated that patients receiving statin therapy had better all-cause mortality outcomes and did not display an increase in the risk of recurrent $\mathrm{ICH}$. 


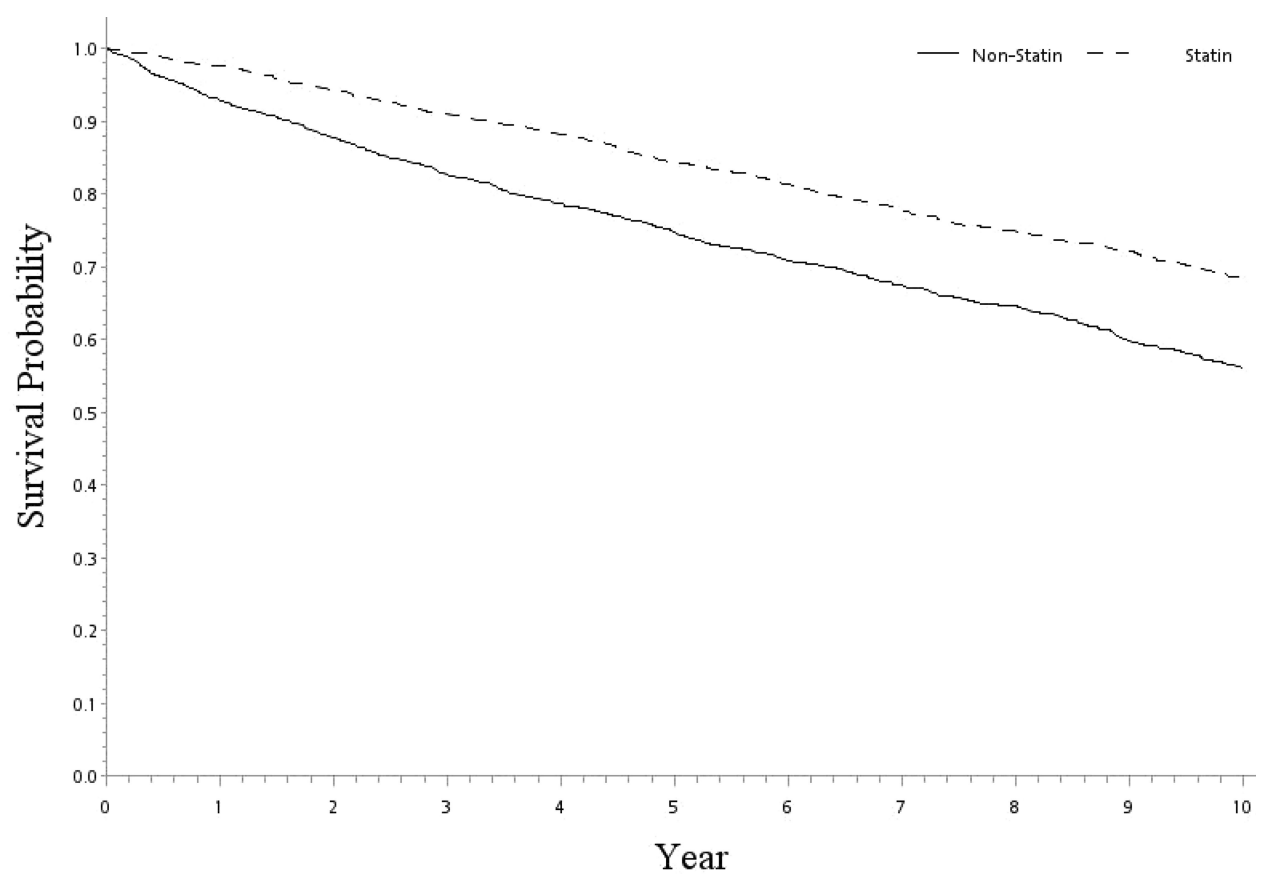

Figure I Survival probability between statin and non-statin cohorts.

In our study, we found that crude and adjusted HRs for mortality related to ICH were higher in old group. Stroke is far more common in the geriatric population, and associations between risk factors for acute stroke and the clinical outcomes are stronger among older adults. However, the knowledge gleaned from research on older adults cannot always be applied to younger adults. The cause of these elevated LDL levels in most younger people is probably genetic as opposed to lifestyle factors. The genetic factors increase the need to prescribe statins. Furthermore, our study may encourage planning of randomized placebo-controlled trials on statin use in young $\mathrm{ICH}$ patients to definitively confirm the effectiveness of statins as secondary prevention after stroke at young age.

Our study had some advantages. First, high cholesterol levels contribute to blood vessel disease that often leads to ischemic stroke. Statins do not just lower cholesterol levels but also reduce the risk of fatty plaques breaking off from the walls of the arteries, reducing the risk of ischemic stroke. ${ }^{27}$ However, previous research exploring the statin-associated risk of ICH in populations with a history of ischemic stroke, not ICH. Therefore, in our study, we focused on the safety of statin treatment after ICH. Second, we selected patients with ICH based on a catastrophic illness certificate. In Taiwan, an individual can apply for a catastrophic illness certificate after being diagnosed with a condition classified as a catastrophic illness by the Ministry of Health and Welfare. Patients with catastrophic illness certification who receive care for the illness or related conditions within the validity period of the certificate do not need to pay a co-payment for outpatient or inpatient care. Therefore, information on ICH diagnoses had high authenticity, limiting the risk of information bias.

Our study also has some limitations. First, we matched the patients with potential confounders. The selected baseline characteristics were balanced between the study groups, except for cerebrovascular disease, anticoagulant agents, antihypertensive agents, NSAIDs, and SSRIs. Patients from the statin group displayed these characteristics more than patients from the non-statin group. Despite this imbalance, the all-cause mortality was lower in statin users. Second, the

Table 3 Survival Probability Between Statin and Non-Statin Cohorts

\begin{tabular}{|l|l|l|l|l|l|l|l|l|l|l|l|}
\hline No. at Risk & Start & Ist & 2nd & 3rd & 4th & 5th & 6th & 7th & 8th & 9th & 10th \\
\hline Non-Statin & 1702 & 1547 & 1436 & 1336 & 1247 & 1084 & 945 & 807 & 684 & 557 & 451 \\
Statin & 1702 & 1627 & 1549 & $147 \mid$ & 1413 & 1299 & 1115 & 956 & 811 & 692 & 557 \\
\hline
\end{tabular}




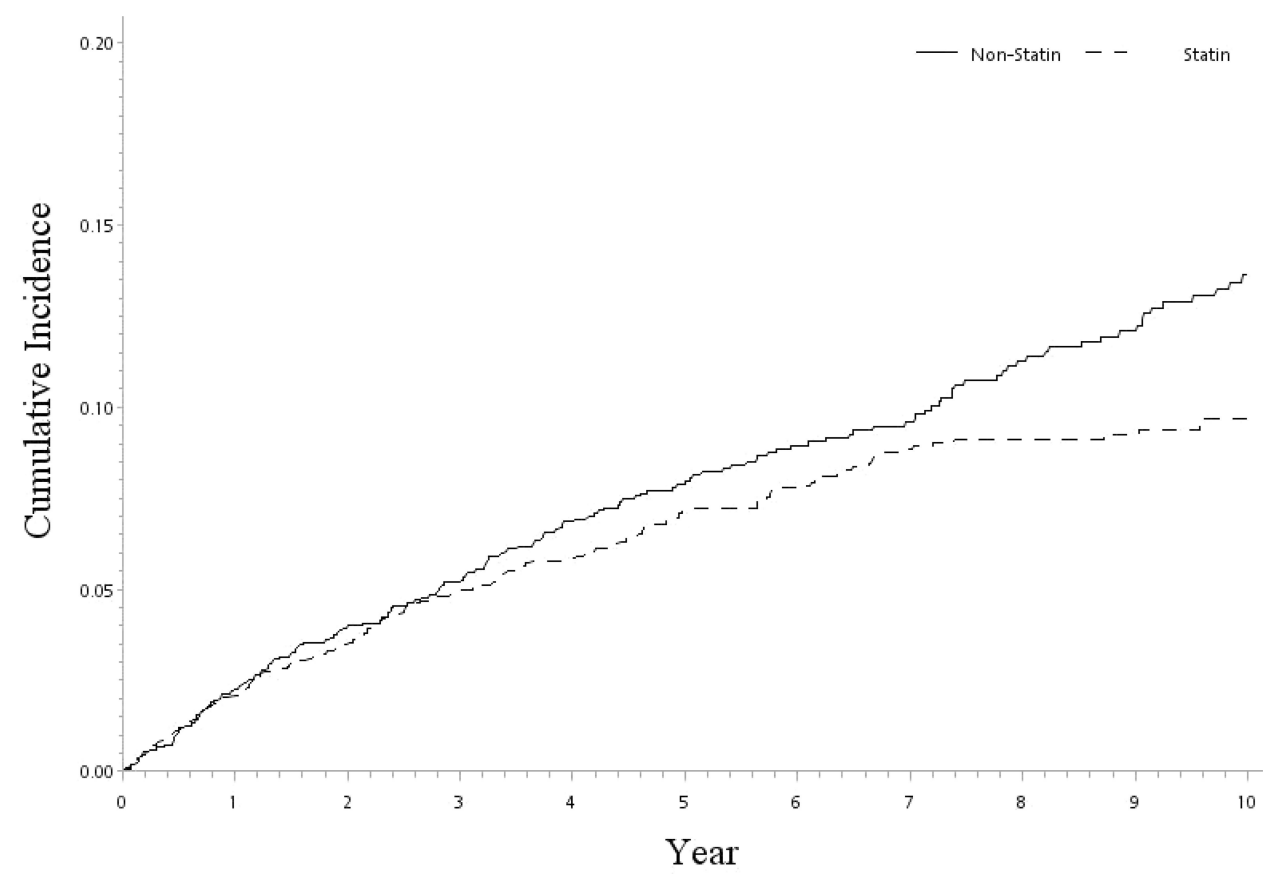

Figure 2 Cumulative Incidence of re-intracerebral hemorrhage between statin and non-statin cohorts.

NHI program was initiated in 1995 in Taiwan, and the NHI Database only allows us to trace the use of medical services as far back as 1996. We could not rule out the patients who were diagnosed with previous stroke before 1996. The NHI database also does not include important parameters such as values of lipid level or lifestyle variables, including smoking or drinking. We could not directly evaluate the association between LDL-C level and ICH incidence. Statins seem to have different effects depending on the cause of the stroke,

Table 4 All-Cause Mortality of the Intracerebral Hemorrhage Population

\begin{tabular}{|l|l|l|}
\hline \multirow{2}{*}{ All-Cause Mortality } & \multicolumn{2}{|l|}{ Intracerebral Hemorrhage } \\
\cline { 2 - 3 } & Non-Statin & Statin \\
\hline All-cancer & 105 & 97 \\
\hline CVD & & \\
CHD & 62 & 74 \\
Ischemic stroke & 151 & 61 \\
Hemorrhagic stroke & 25 & 22 \\
\hline Diabetes & 71 & 63 \\
Injury & 6 & 7 \\
Respiratory diseases & 28 & 12 \\
Liver cirrhosis & 14 & 6 \\
Kidney diseases & 20 & 26 \\
Suicide & 2 & 6 \\
Other & 244 & 183 \\
\hline
\end{tabular}

either ischemic or hemorrhagic. Also, there are different statins with different dosages. ${ }^{27}$ In addition, high-intensity statins have more benefits for secondary prevention of cardiovascular disease. Statin withdrawal may have a harmful effect on the long-term neurologic outcome. However, statin intensity might have been influenced by underlying demographics, clinical presentation at admission, baseline lipid values, and physician's preference. ${ }^{28,29}$ Therefore, it is hard to detect the statin dosage effect. Third, the patients were not randomly assigned to either the statin-treatment or nontreatment group in our cohort study. It was impossible to monitor when the patients started to take statins. Lastly, the location of the hematoma or cerebral amyloid angiopathy might be associated with the risk of recurrent $\mathrm{ICH}$ and longterm functional outcome. ICD 9 Codes cannot reliably identify hemorrhagic transformation of ischemic stroke. However, the information were unavailable in the claims database.

\section{Conclusion}

Our nationwide cohort study demonstrated the protective effects of statins on all-cause mortality in patients with newly diagnosed $\mathrm{ICH}$. We also found that recurrence of $\mathrm{ICH}$ after the primary $\mathrm{ICH}$ event was not significantly different based on whether patients received statins. Our findings suggest that statin therapy post ICH may be safe. A careful interpretation of our findings is needed, 
Table 5 Prediction for Occurrence of Death (Intracerebral Hemorrhage Cohort)

\begin{tabular}{|c|c|c|c|c|}
\hline & \multirow{2}{*}{$\begin{array}{l}\text { Crude } \\
\text { SHR }\end{array}$} & \multirow[t]{2}{*}{ p-value } & \multirow{2}{*}{$\begin{array}{l}\text { Adjusted } \\
\text { SHR }\end{array}$} & \multirow[t]{2}{*}{ p-value } \\
\hline & & & & \\
\hline Statin vs non-statin & $0.68(0.61-0.76)^{*}$ & $<0.0001$ & $0.65(0.58-0.73)^{*}$ & $<0.0001$ \\
\hline Age & $1.07(1.07-1.08)^{*}$ & $<0.0001$ & $1.07(1.06-1.08)^{*}$ & $<0.0001$ \\
\hline Male vs female & $0.96(0.86-1.07)$ & 0.4275 & $1.24(1.10-1.39)^{*}$ & 0.0003 \\
\hline \multicolumn{5}{|l|}{ Medication } \\
\hline Antithrombotic agents & NA & & NA & \\
\hline Anticoagulant agents & $1.53(1.03-2.27)^{*}$ & 0.0359 & $1.20(0.79-1.83)$ & 0.3811 \\
\hline Antihypertensive agents & $0.75(0.66-0.86)^{*}$ & $<0.0001$ & $0.87(0.76-1.00)^{*}$ & 0.0481 \\
\hline NSAIDs & $1.02(0.90-1.16)$ & 0.7742 & $1.00(0.87-1.14)$ & 0.975 \\
\hline SSRIs & $0.96(0.86-1.08)$ & 0.531 & $0.96(0.85-1.08)$ & 0.5075 \\
\hline \multicolumn{5}{|l|}{ Comorbidities } \\
\hline Myocardial infarct & $1.6 \mathrm{I}(1.27-2.04)^{*}$ & 0.0001 & $1.19(0.93-1.52)$ & 0.1749 \\
\hline Congestive heart failure & $2.30(1.92-2.75)^{*}$ & $<0.0001$ & $1.54(1.27-1.88)^{*}$ & $<0.0001$ \\
\hline Peripheral vascular disease & $1.78(1.33-2.38)^{*}$ & 0.0001 & $1.43(1.06-1.93)^{*}$ & 0.0183 \\
\hline Cerebrovascular disease & $1.46(1.31-1.63)^{*}$ & $<0.0001$ & $1.12(0.99-1.26)$ & 0.0629 \\
\hline Dementia & $3.57(2.81-4.55)^{*}$ & $<0.0001$ & $1.42(1.10-1.84)^{*}$ & 0.0074 \\
\hline Chronic lung disease & $1.53(1.36-1.73)^{*}$ & $<0.0001$ & $0.97(0.85-1.11)$ & 0.6617 \\
\hline Connective tissue disease & $1.65(1.10-2.47)^{*}$ & 0.0156 & $1.07(0.7|-| .63)$ & 0.7423 \\
\hline Ulcer & $1.33(1.18-1.50)^{*}$ & $<0.0001$ & $0.90(0.79-1.02)$ & 0.1107 \\
\hline Chronic liver disease & $1.11(0.95-1.29)^{*}$ & 0.1988 & $0.94(0.80-1.11)$ & 0.4942 \\
\hline Diabetes & $1.75(1.56-1.97)^{*}$ & $<0.0001$ & $1.43(1.26-1.63)^{*}$ & $<0.0001$ \\
\hline Diabetes with end organ damage & $2.42(2.05-2.85)^{*}$ & $<0.0001$ & $1.45(1.20-1.75)^{*}$ & 0.0001 \\
\hline Hemiplegia & $1.59(1.06-2.38)^{*}$ & 0.0251 & $0.95(0.63-1.43)$ & 0.7906 \\
\hline Moderate or severe kidney disease & $2.03(1.70-2.42)^{*}$ & $<0.0001$ & $\mathrm{I} .46(\mathrm{I} .2 \mathrm{I}-\mathrm{I} .75)^{*}$ & 0.0001 \\
\hline Tumor, leukemia, lymphoma & $2.49(2.00-3.10)^{*}$ & $<0.0001$ & $1.61(1.27-2.04)^{*}$ & 0.0001 \\
\hline Moderate or severe liver disease & $4.60(1.48-14.3)^{*}$ & 0.0083 & $2.09(0.66-6.64)$ & 0.2104 \\
\hline Malignant tumor, metastasis & $2.81(1.51-5.24)^{*}$ & 0.0011 & $1.33(0.68-2.59)$ & 0.3980 \\
\hline
\end{tabular}

Note: *Indicating $\mathrm{P}<0.05$.

considering that the interpretations of our results are limited. Large-scale randomized controlled trials are needed to further confirm our findings.

\section{Disclosure}

The authors report no conflicts of interest for this work.

\section{References}

1. Hemphill JC, Greenberg SM, Anderson CS, et al., American Heart Association Stroke Council; Council on Cardiovascular and Stroke Nursing; Council on Clinical Cardiology. Guidelines for the management of spontaneous intracerebral hemorrhage: a guideline for healthcare professionals from the American Heart Association/American Stroke Association. Stroke. 2015;46(7):2032-2060. doi:10.1161/STR.00000000 00000069

2. Ikram MA, Wieberdink RG, Koudstaal PJ. International epidemiology of intracerebral hemorrhage. Curr Atheroscler Rep. 2012;14 (4):300-306. doi:10.1007/s11883-012-0252-1

3. Castilla-Guerra L, Del Carmen Fernandez-Moreno M, ColmeneroCamacho MA. Statins in stroke prevention: present and future. Curr Pharm Des. 2016;22(30):4638-4644. doi:10.2174/1381612822666160510 125229
4. Amarenco P, Tonkin AM. Statins for stroke prevention: disappointment and hope. Circulation. 2004;109(Suppl 23_suppl_1):III44-9. doi:10.1161/01.CIR.0000131518.25959.8F

5. Lee YC, Hung SY, Wang HK, et al. Is there different risk of cancer among end-stage renal disease patients undergoing hemodialysis and peritoneal dialysis? Cancer Med. 2018;7(2):485-498. doi:10.1002/ cam4.1289

6. Feng MC, Lin YC, Chang YH, et al. The mortality and the risk of aspiration pneumonia related with dysphagia in stroke patients. J Stroke Cerebrovasc Dis. 2019;28(5):1381-1387. doi:10.1016/j. jstrokecerebrovasdis.2019.02.011

7. Liang CY, Chen DY, Mao CT, et al. Cardiovascular risk of sitagliptin in ischemic stroke patients with type 2 diabetes and chronic kidney disease: a nationwide cohort study. Medicine (Baltimore). 2018;97 (52):e13844. doi:10.1097/MD.0000000000013844

8. Chen YY, Yen YF, Lin JX, et al. Risk of ischemic stroke, hemorrhagic stroke, and all-cause mortality in retinal vein occlusion: a nationwide population-based cohort study. $J$ Ophthalmol. 2018;2018:8629429. doi:10.1155/2018/8629429

9. Lee M, Saver JL, Wu YL, et al. Utilization of statins beyond the initial period after stroke and 1-year risk of recurrent stroke. $J$ Am Heart Assoc. 2017;6(8):e005658. doi:10.1161/JAHA.117.00 5658

10. Ruiz-León AM, Lapuente M, Estruch R, Casas R. Clinical advances in immunonutrition and atherosclerosis: a review. Front Immunol. 2019;10:837. doi:10.3389/fimmu.2019.00837 
11. Schaftenaar F, Frodermann V, Kuiper J, Lutgens E. Atherosclerosis: the interplay between lipids and immune cells. Curr Opin Lipidol. 2016;27(3):209-215. doi:10.1097/MOL.0000000000000302

12. Tramacere I, Boncoraglio GB, Banzi R, et al. Comparison of statins for secondary prevention in patients with ischemic stroke or transient ischemic attack: a systematic review and network meta-analysis. BMC Med. 2019;17(1):67. doi:10.1186/s12916-019-1298-5

13. Ziff OJ, Banerjee G, Ambler G, Werring DJ. Statins and the risk of intracerebral haemorrhage in patients with stroke: systematic review and meta-analysis. J Neurol Neurosurg Psychiatry. 2019;90 (1):75-83. doi:10.1136/jnnp-2018-318483

14. Lei $\mathrm{C}, \mathrm{Wu} \mathrm{B}, \mathrm{Liu} \mathrm{M}$, Chen Y. Association between statin use and intracerebral hemorrhage: a systematic review and meta-analysis. Eur $J$ Neurol. 2014;21(2):192-198. doi:10.1111/ene.12273

15. Scheitz JF, MacIsaac RL, Abdul-Rahim AH, et al. VISTA collaboration. Statins and risk of poststroke hemorrhagic complications. Neurology. 2016;86(17):1590-1596. doi:10.1212/WNL.0000000000 002606

16. Ma C, Gurol ME, Huang Z, et al. Low-density lipoprotein cholesterol and risk of intracerebral hemorrhage: a prospective study. Neurology. 2019;93(5):e445-e457. doi:10.1212/WNL.0000000000007853

17. Chang JJ, Katsanos AH, Khorchid Y, et al. Higher low-density lipoprotein cholesterol levels are associated with decreased mortality in patients with intracerebral hemorrhage. Atherosclerosis. 2018;269:14-20. doi:10.1016/j.atherosclerosis.2017.12.008

18. Navarese EP, Robinson JG, Kowalewski M, et al. Association between baseline LDL-C level and total and cardiovascular mortality after LDL-C lowering: a systematic review and meta-analysis. JAMA. 2018;319(15):1566-1579. doi:10.1001/jama.2018.2525

19. Ravnskov U, Diamond DM, Hama R, et al. Lack of an association or an inverse association between low-density-lipoprotein cholesterol and mortality in the elderly: a systematic review. BMJ Open. 2016;6(6):e010401. doi:10.1136/bmjopen-2015-010401

20. Lin HC, Tsai WC, Lin JR, et al. Adjunctive statin therapy reduces intracranial hemorrhage and 1-year mortality in patients with atrial fibrillation after acute ischemic stroke: a population-based epidemiological study from Taiwan. J Clin Neurosci. 2019;69:224-229. doi:10.1016/j.jocn.2019.07.045
21. Lin MS, Lin YS, Chang ST, et al. Effect of initiating statin therapy on long-term outcomes of patients with dyslipidemia after intracerebral hemorrhage. Atherosclerosis. 2019;288:137-145. doi:10.1016/j. atherosclerosis.2019.07.009

22. Chung CM, Lin MS, Liu CH, et al. Discontinuing or continuing statin following intracerebral hemorrhage from the view of a national cohort study. Atherosclerosis. 2018;278:15-22. doi:10.1016/j.atherosclerosis. 2018.08.049

23. Jukema JW, Zijlstra LE, Bhatt DL, et al. Odyssey outcomes investigators. Effect of alirocumab on stroke in Odyssey outcomes. Circulation. 2019;140(25):2054-2062. doi:10.1161/CIRCULATIONAHA.119.043 826

24. Ribe AR, Vestergaard CH, Vestergaard M, et al. Statins and risk of intracerebral hemorrhage in individuals with a history of stroke. Stroke. 2020;51(4):1111-1119. doi:10.1161/STROKEAHA.119.027 301

25. Ribe AR, Vestergaard $\mathrm{CH}$, Vestergaard $\mathrm{M}$, et al. Statins and risk of intracerebral haemorrhage in a stroke-free population: a nationwide Danish propensity score matched cohort study. EClinicalMedicine. 2019;8:78-84. doi:10.1016/j.eclinm.2019.02.007

26. McKinney JS, Kostis WJ. Statin therapy and the risk of intracerebral hemorrhage: a meta-analysis of 31 randomized controlled trials. Stroke. 2012;43(8):2149-2156. doi:10.1161/STROKEAHA.112.655 894

27. Vitturi BK, Gagliardi RJ. Effects of statin therapy on outcomes of ischemic stroke: a real-world experience in Brazil. Arq Neuropsiquiatr. 2020;78(8):461-467. doi:10.1590/0004-282x20200027

28. Kim J, Park KT, Jang MJ, et al. High-intensity versus non-highintensity statins in patients achieving low-density lipoprotein cholesterol goal after percutaneous coronary intervention. J Am Heart Assoc. 2018;7(21):e009517. doi:10.1161/JAHA.118.009517

29. Vitturi BK, Gagliardi RJ. The influence of statin withdrawal and adherence on stroke outcomes. Neurol Sci. 2020. doi:10.1007/ s10072-020-04790-y
Risk Management and Healthcare Policy

\section{Publish your work in this journal}

Risk Management and Healthcare Policy is an international, peerreviewed, open access journal focusing on all aspects of public health, policy, and preventative measures to promote good health and improve morbidity and mortality in the population. The journal welcomes submitted papers covering original research, basic science, clinical \& epidemiological studies, reviews and evaluations, guidelines, expert opinion and commentary, case reports and extended reports. The manuscript management system is completely online and includes a very quick and fair peer-review system, which is all easy to use. Visit http://www.dovepress.com/testimonials.php to read real quotes from published authors. 